\title{
Finite element analysis for transcatheter aortic valve replacement: More than a seer reading the future!
}

\author{
Michele Di Mauro, MD, ${ }^{a}$ Luca Paolo Weltert, MD, ${ }^{b}$ Sotirios Prapas, MD, ${ }^{c}$ and Antonio M. Calafiore, $\mathrm{MD}^{\mathrm{c}}$
}

\author{
From the ${ }^{\mathrm{a} D e p a r t m e n t}$ of Cardiac Surgery, University of Chieti, Chieti; ${ }^{\mathrm{b}}$ Department of Cardiac Surgery, Euro- \\ pean Hospital, Rome, Italy; and ${ }^{\mathrm{c} D e p a r t m e n t}$ of Cardiac Surgery, Henry Durant Hospital, Athens, Greece. \\ Disclosures: Authors have nothing to disclose with regard to commercial support. \\ Received for publication Dec 27, 2016; accepted for publication Jan 5, 2017; available ahead of print Feb 22, \\ 2017. \\ Address for reprints: Michele Di Mauro, MD, Department of Cardiac Surgery, SS Annunziata Hospital, Via dei \\ Vestini, 66100 Chieti, Italy (E-mail: mdimauro1973@gmail.com). \\ J Thorac Cardiovasc Surg 2017;153:1074-5 \\ $0022-5223 / \$ 36.00$ \\ Copyright (c) 2017 by The American Association for Thoracic Surgery \\ http://dx.doi.org/10.1016/j.jtcvs.2017.01.020
}

The science of geometric algorithmic prediction of stress and strain coefficients in complex structures by dividing them into small geometric areas whose behavior is mathematically predictable is known as finite element analysis (FEA). It has made, in 15 years of development in the context of cardiovascular surgery, not rapid but solid progress.

FEA has had little influence on clinical practice so far, very likely because of the diffidence of surgeons toward speculative data without related clinical evidence. It was easy to do without FEA; there were more comprehensible and perhaps even more reliable ways to test and prove theses and hypotheses. The recent tumultuous technologic evolution in surgery with the advent of transcatheter aortic valve replacement (TAVR) and the rapid progress from one to another generation of prosthesis have given a new impetus to FEA, as well attested by the article of Xuan and colleagues ${ }^{1}$ in this issue of the Journal.

In fact, the durability of the TAVR is just such a hot topic. As long as TAVR was reserved for patients at prohibitive risk with no other chances, mere evidence of feasibility and short-term success were more than enough. ${ }^{2,3}$ Now that the ambition moves toward the inclusion of patients at intermediate ${ }^{4}$ and low risk, however, we could make potential evaluation mistakes concerning long-term outcomes of patients undergoing TAVR on the basis of the current enthusiasm, only to severely regret it in the future.

The article by Xuan and colleagues ${ }^{1}$ in this issue of the Journal is a fine example of how the current state of FEA research can help the decision-making process. The article presents a sophisticated, but reproducible and understandable, analysis of the first-generation Edwards Sapien valve for TAVR (Edwards Lifesciences Corporation, Irvine Calif). The strength of this study is the chance to take into account for the first time the assembly of the valve and the actual thicknesses of the leaflets. In fact, Xuan and colleagues ${ }^{1}$ were able to determine the existence of areas of significantly higher stress at the level of the commissural

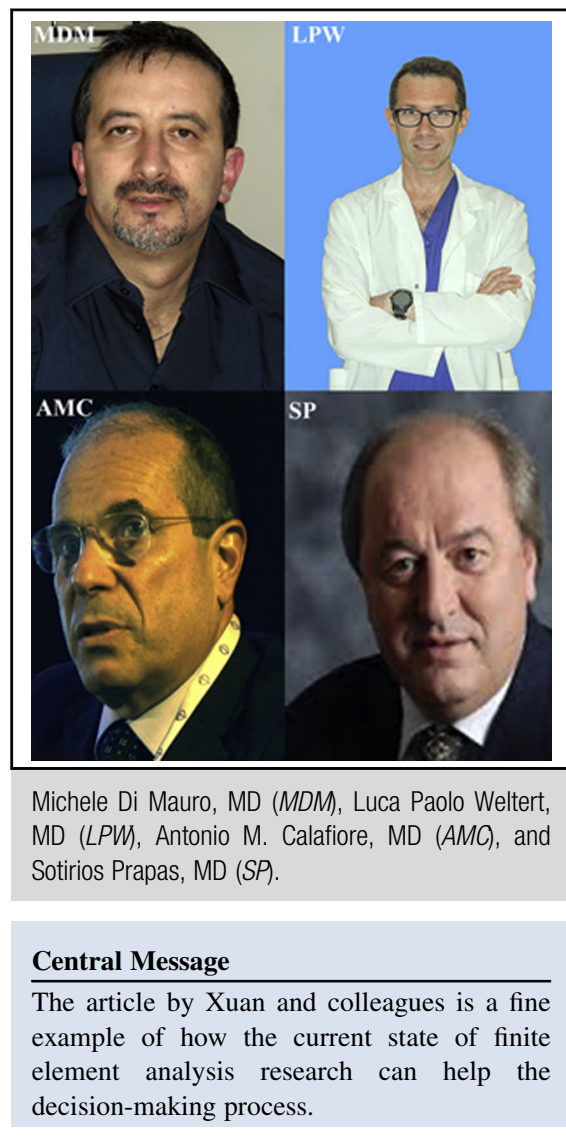

See Article page 1065 .

tip and at the annular level of proximal deployment, where longitudinal motion was constrained. These conditions, along with distorted noncylindric TAVR, may lead to an accelerated structural degeneration.

In the same field, previous studies have already demonstrated, either in an unfatigued state ${ }^{5}$ or in a fatigue simulation, ${ }^{6}$ that the predictable durability of TAVR is inferior to that of surgically implanted aortic bioprostheses, confirming that the leaflet strains and stresses are significantly higher in TAVR, especially near commissures and along the stent attachments. The future challenge is to use FEA to evaluate the possible damaging action of the crimping process, taking into account that TAVR leaflets are thinner than surgically replaced valve leaflets and that the next generation (Sapien 3 ) with 14F delivery systems requires thinner leaflets.

More and more in the future, some understanding of bioengineering will be required of the clinical surgeon for 
the proper and timely assessment of the efficiency and safety of the new devices that gradually will enter the market. We may soon no longer have the luxury of letting time itself assess the durability of a device.

\section{References}

1. Xuan Y, Krishnan K, Ye J, Dvir D, Guccione JM, Ge L, et al. Stent and leaflet stresses in a 26-mm first-generation balloon-expandable transcatheter aortic valve. J Thorac Cardiovasc Surg. 2017;153:1065-73.

2. Leon MB, Smith CR, Mack M, Miller DC, Moses JW, Svensson LG, et al; PARTNER Trial Investigators. Transcatheter aortic-valve implantation for aortic stenosis in patients who cannot undergo surgery. $N$ Engl J Med. 2010;363: 1597-607.

3. Smith CR, Leon MB, Mack MJ, Miller DC, Moses JW, Svensson LG, et al; PARTNER Trial Investigators. Transcatheter versus surgical aortic-valve replacement in high-risk patients. $N$ Engl J Med. 2011;364:2187-98.

4. Leon MB, Smith CR, Mack MJ, Makkar RR, Svensson LG, Kodali SK, et al; PARTNER 2 Investigators. Transcatheter or surgical aortic-valve replacement in intermediate-risk patients. N Engl J Med. 2016;374:1609-20.

5. Li K, Sun W. Simulated thin pericardial bioprosthetic valve leaflet deformation un der static pressure-only loading conditions: implications for percutaneous valves. Ann Biomed Eng. 2010;38:2690-701.

6. Martin C, Sun W. Comparison of transcatheter aortic valve and surgical bioprosthetic valve durability: a fatigue simulation study. J Biomech. 2015;48:3026-34. 